\title{
Dunaliella salina microalga pressurized liquid extracts as potential antimicrobials
}

Miguel Herrero ${ }^{1}$, Elena Ibáñez ${ }^{1}$, Alejandro Cifuentes ${ }^{1}$, F. Javier Señorans ${ }^{2}$, Guillermo Reglero $^{2}$, Susana Santoyo ${ }^{2 *}$

${ }^{1}$ Instituto de Fermentaciones Industriales, CSIC, Juan de la Cierva 3, 28006 Madrid, Spain.

${ }^{2}$ Sección Departamental Ciencias de la Alimentación, Universidad Autónoma de Madrid, Ciudad Universitaria de Cantoblanco, 28049 Madrid, Spain.

Keywords: antimicrobial, Dunaliella salina, microalgae, pressurized liquid extraction

Short title: Dunaliella salina PL extracts as antimicrobials

${ }^{*}$ Corresponding author:

Susana Santoyo

Sección Departamental de Ciencias de la Alimentación

Facultad de Ciencias, Módulo C-XVI, 505. Universidad Autónoma de Madrid

Ctra. Colmenar Km 15. 28049 Madrid, Spain

Phone: 34914973778

Fax: 34914973778

E-mail: susana.santoyo@uam.es 


\section{Abstract.}

In the present work, the antimicrobial activity of different pressurized liquid extracts obtained from Dunaliella salina microalga has been tested against several microorganisms of importance for the food industry (Escherichia coli, Staphylococcus aureus, Candida albicans and Aspergillus niger). Different solvents (hexane, petroleum ether, hexane and water) and extraction conditions (40, 100 and $160^{\circ} \mathrm{C}$ ) have been tested. Results showed that the best antimicrobial activity was obtained, for each solvent, at the highest extraction temperature $\left(160^{\circ} \mathrm{C}\right)$. Likewise, the extraction yield followed the same trend increasing with the extraction temperature and being maximum when ethanol was employed as extraction solvent. Water extracts provided the lowest extraction yields. In general, the best results in terms of antimicrobial activity were obtained using petroleum ether and hexane, although ethanolic extracts presented also good antimicrobial activity. Since the main antimicrobial activity of the extracts was against bacteria, the extracts can be considered to show specifically antibacterial effect. The extracts were analyzed by GC-MS in order to identify the compounds responsible of such activity. 15 different volatile compounds as well as several fatty acids (mainly palmitic, $\alpha$-linolenic and oleic acids) that could be responsible for the antimicrobial activity were identified in the extracts. $\beta$-cyclocitral, $\alpha$ - and $\beta$-ionone, neophytadiene, and phytol were identified among other volatile compounds; all of these compounds have previously been described as antimicrobial agents. 